\title{
Therapeutic Effects of Interventional Therapy and Conservative Therapy on Lower Extremity Arteriosclerosis Obliterans and Risk Factors for Prognosis
}

\author{
Lingxiong Chen ${ }^{1}$, Xuming Zhang ${ }^{1, *}$, Fuyan Jiang ${ }^{1}$, Zhida Yin ${ }^{1}$, Jinqiu Xue ${ }^{1}$, Chengmei Ruan ${ }^{1}$, Lijiao Xie ${ }^{2}$ \\ ${ }^{1}$ Department of Interventional Medicine, Fujian Medical University Affiliated Mindong Hospital, Fu'an, Fujian Province 355000, P. R. China \\ ${ }^{2}$ Department of Radiological Imaging, Fujian Medical University Affiliated Mindong Hospital, Fu'an, Fujian Province 355000, P. R. China
}

\section{ARTICLE INFO}

Article History

Received 20 September 2020

Accepted 24 January 2021

Keywords

Lower extremity

arteriosclerosis obliterans

interventional therapy

conservative therapy

risk factor

prognosis

\begin{abstract}
Background: Arteriosclerosis Obliterans (ASO) is an important cause for lower limb amputation. We aimed to compare the effects of interventional and conservative therapies on lower extremity ASO, and to analyze the risk factors for prognosis.

Methods: Ninety-eight eligible patients were randomly divided into experimental $(n=50)$ and control groups $(n=48)$. Conservative therapy was conducted for control group, and experimental group was given conservative and interventional therapies. Their baseline clinical data, hospital stay length, claudication distance, Rutherford stage, diseased arteries, AnkleBrachial Index (ABI), clinical outcomes and adverse events were recorded. Then they were divided into poor $(n=31)$ and good prognosis groups $(n=67)$, and risk factors were explored by univariate and multivariate analyses.

Results: The hospital stay length of experimental group was significantly shorter than that of control group ( $p<0.05)$. After treatment, Rutherford stage decreased, and vascular patency rate and total response rate rose in experimental group $(p<0.05)$. Claudication distance and ABI significantly increased in both groups compared with those before treatment, especially in experimental group $(p<0.05)$. The incidence rates of cardiovascular and cerebrovascular events, amputation and death were significantly lower in experimental group $(p<0.05)$. Age, conservative therapy, smoking, hypertension, diabetes mellitus, hyperlipidemia and fibrinogen were independent risk factors for poor prognosis $(p<0.05)$. Age of $>70$ years old and fibrinogen level of $>4 \mathrm{~g} / \mathrm{L}$ had greater effects on prognosis.
\end{abstract}

Conclusion: Interventional therapy works well for lower extremity ASO, with high safety, easy recovery and mild complications. Poor prognosis is caused by old age, conservative therapy, smoking, hypertension, diabetes mellitus, hyperlipidemia and increased fibrinogen.

(C) 2021 The Authors. Publishing services by Atlantis Press International B.V. This is an open access article distributed under the CC BY-NC 4.0 license (http://creativecommons.org/licenses/by-nc/4.0/).

\section{INTRODUCTION}

Lower extremity Arteriosclerosis Obliterans (ASO) refers to the lesions of limb ischemia and necrosis caused by insufficient blood supply due to the formation of atherosclerotic plaques, as a part of the development process of systemic atherosclerotic lesion. With the improvement of living standards, extension of lifespan and significant increase in metabolic diseases such as diabetes mellitus, the incidence rate of lower extremity ASO has risen annually [1]. ASO is an important cause for the amputation of lower limbs, which seriously affects the quality of life of patients and raises the risk of death.

At present, lower extremity ASO is treated with vascular interventional therapy and bypass surgery. To avoid large surgical trauma, minimally invasive interventional therapy, also known as

"Corresponding author.Email: gonzalezthomas53@yahoo.com

Peer review under responsibility of the Association for Research into Arterial Structure and Physiology

Data availability statement: The original data are available from the corresponding author [XZ], upon reasonable request.
Percutaneous Transluminal Angioplasty (PTA), including balloon dilation and stent implantation, is mostly used currently. In recent years, the vascular interventional therapy for lower extremities has developed rapidly in China. However, there are some deficiencies in the preoperative evaluation of patients and the control of postoperative metabolic indices, accompanied by short follow-up period, small sample size and low success rate of surgery [2]. In this study, therefore, the therapeutic effects of interventional therapy and conservative therapy on ASO were compared, and the risk factors for prognosis were analyzed, aiming to provide a valuable evidence for clinical treatment.

\section{MATERIALS AND METHODS}

\subsection{Baseline Clinical Data}

A total of 98 patients with lower extremity ASO treated in our hospital from July 2016 to October 2018 were selected and divided into experimental group $(n=50)$ and control group $(n=48)$ using a random number table. For experimental group, interventional 
therapy was performed besides conservative therapy. This group included 35 males and 15 females aged 43-86 years old, with an average of $(65.41 \pm 6.27)$ years. The duration of disease was $2-8$ years, with an average of $(4.38 \pm 1.42)$ years. The diseased arteries included 26 inferior genicular arteries, 27 femoral popliteal arteries and 30 iliac arteries. In terms of comorbidities, there were 14 cases of heart disease, 32 cases of hypertension, nine cases of diabetes mellitus, 12 cases of cerebrovascular disease, 16 cases of chronic renal insufficiency, 25 cases of hyperlipidemia, 30 cases of hypoproteinemia and 13 cases of anemia. For control group, conservative therapy alone was performed. This group included 32 males and 16 females aged 43-85 years old, with an average of $(64.83 \pm 6.25)$ years. The duration of disease was $2-9$ years, with an average of $(4.47 \pm 1.46)$ years. The diseased arteries included 22 inferior genicular arteries, 24 femoral popliteal arteries and 27 iliac arteries. In terms of comorbidities, there were 14 cases of heart disease, 30 cases of hypertension, eight cases of diabetes mellitus, 11 cases of cerebrovascular disease, 12 cases of chronic renal insufficiency, 24 cases of hyperlipidemia, 29 cases of hypoproteinemia and 15 cases of anemia.

\subsection{Related Criteria}

Diagnostic criteria [3]: The patients were aged $>40$ years old; there were high-risk factors such as smoking, hypertension, hyperlipidemia and diabetes mellitus; there were clinical manifestations of ASO; the arterial pulsation at the distal ischemic limb weakened or disappeared; the Ankle-Brachial Index (ABI) was $\leq 0.9$; stenosis or occlusion of corresponding arteries was found through color Doppler ultrasonography, computed tomographic angiography, magnetic resonance angiography and digital subtraction angiography. ASO can be diagnosed if the first four of the above diagnostic criteria were met.

Inclusion criteria: (1) Patients who met the above diagnostic criteria for ASO; (2) those with complete clinical data; (3) those who and whose families were informed of this study and participated voluntarily.

Exclusion criteria: (1) Patients complicated with malignant tumors or dysfunction of vital organs such as the liver and kidney; (2) those with coagulation dysfunction; (3) those with mental disorders such as schizophrenia or depression. This study has been reviewed and approved by the Medical Ethics Committee of our hospital.

\subsection{Treatment Methods}

Antiplatelet therapy was conducted for control group in addition to controlling blood pressure, lipid and glucose levels. For experimental group, interventional therapy was conducted based on the treatment for control group. After local anesthesia, the femoral artery was punctured, a catheter sheath was inserted into the blood vessel and heparin was injected. The arterial stenosis and occlusion of lower limbs were fully checked through angiography, and the puncture point was determined. Then catheter and guide wire were inserted through the catheter sheath, the distal end was explored until near the site of vascular occlusion, and the occlusion site was opened by slowly twisting the "J"-shaped hydrophilic guide wire. Alternatively, a microballoon was inserted into the inferior genicular arteries for PTA. A $6 \mathrm{~F}$ catheter was placed into the femoral artery on the unaffected side, a $5 \mathrm{~F}$ angiographic catheter was penetrated through the arterial stenosis site of lower limbs, a hard guide wire was replaced, and the balloon catheter was also pushed forward to expand the arterial stenosis and occlusion sites. If the arterial stenosis rate shown in angiography was still higher than $30 \%$ after expansion, an ev3 intravascular stent was placed at the stenosis segment. If complete occlusion occurred, thrombectomy was performed first, and then the stent was placed. After the vascular patency was confirmed by angiography, drug was infused into the artery through the catheter to complete the surgery. Subsequently, the patients were given anticoagulation therapy to improve the blood coagulation function, thereby avoiding deep vein thrombosis caused by platelet aggregation. After discharge, the patients were asked to undergo long-term antiplatelet therapy and to exercise frequently, and reexamined in the hospital every 6 months. Once vascular stenosis was found, they were treated promptly. The patients were followed up for 1 year.

\subsection{Observation Indices}

The age, gender, duration of disease, drinking history and smoking history of patients, and whether they were complicated with hypertension, heart disease, diabetes mellitus, cerebrovascular disease, chronic renal insufficiency, hyperlipidemia, fibrinogen elevation, hypoproteinemia and anemia were recorded. Before treatment, the fasting venous blood was collected, and the white blood cell, platelet and lymphocyte counts were detected. The claudication distance, Rutherford stage, diseased arteries and ABI before and after treatment were recorded. ABI is the ratio of systolic pressure of the anterior or posterior tibial artery at the ankle to that of the upper arm (brachial artery).

Rutherford staging criteria [3]: Stage 1: mild intermittent claudication; stage 2: moderate intermittent claudication; stage 3: severe intermittent claudication; stage 4 : rest pain; stage 5 : mild tissue defect; stage 6: tissue ulcer and gangrene. The hospital stay, clinical efficacy, and incidence rates of cardiovascular and cerebrovascular events, amputation and death were compared.

Evaluation criteria for treatment outcomes [4]: Markedly effective: vascular stenosis of $<30 \%$ shown in angiography, disappearance of symptoms and without severe complications; effective: vascular stenosis of $<50 \%$ shown in angiography, ulcer healing rate of $>50 \%$, alleviation of symptoms and without complications. Ulcer healing rate was calculated as follows. Planimetry was performed to measure the ulcer surface area. In detail, a sterile transparent polyurethane film was applied onto a target ulcer after cleaning and drying, and its perimeter was traced with a permanent ultra-finetipped marker. This area was measured in triplicate, and the mean was used. Ulcer healing rate $(\%)=($ ulcer surface area before treatment - ulcer surface area after treatment)/ulcer surface area before treatment $\times 100 \%$. Ineffective: severer vascular stenosis and no alleviation or even aggravation of symptoms. Total response rate $=$ markedly effective rate + effective rate.

\subsection{Statistical Analysis}

SPSS 17.0 software (SPSS Inc, Chicago, IL, USA) was used for data analysis. The quantitative data in line with normal distribution were expressed as $(\bar{x} \pm s)$, and the independent $t$-test was adopted for the 
comparison between two groups. Numerical data were expressed as case (\%), and the $\chi^{2}$ test was used for the comparison between two groups. The risk factors for prognosis were explored using univariate and multivariate logistic regression analyses. The cut-off point in continuous variable stratification was determined by decision tree modeling, and the independent risk factors for prognosis were obtained. $p<0.05$ suggested a statistically significant difference.

\section{RESULTS}

\subsection{Baseline Clinical Data}

The two groups had similar age, gender ratio, duration of disease, claudication distance, ABI, Rutherford stage, diseased arteries, history of smoking and drinking, complication with hypertension, heart disease, diabetes mellitus, cerebrovascular disease, chronic renal insufficiency, hyperlipidemia, hypoproteinemia and anemia, blood fibrinogen level, as well as white blood cell, platelet and lymphocyte counts $(p>0.05)$ (Table 1$)$.

\subsection{Treatment Outcomes}

The hospital stay of experimental group was significantly shorter than that of control group $(p<0.05)$. After treatment, the Rutherford

Table 1 Baseline clinical data $[n(\%)](\bar{x} \pm s)$

\begin{tabular}{|c|c|c|c|c|}
\hline Index & $\begin{array}{l}\text { Experimental } \\
\text { group }(n=50)\end{array}$ & $\begin{array}{c}\text { Control } \\
\text { group }(n=48)\end{array}$ & $\chi^{2} / t$ & $p$ \\
\hline Age (years) & $65.41 \pm 6.27$ & $64.83 \pm 6.25$ & 0.458 & 0.648 \\
\hline Course of disease (years) & $4.38 \pm 1.42$ & $4.47 \pm 1.46$ & 0.309 & 0.758 \\
\hline Claudication distance (m) & $129.58 \pm 13.16$ & $131.49 \pm 13.62$ & 0.706 & 0.482 \\
\hline $\mathrm{ABI}$ & $0.33 \pm 0.11$ & $0.31 \pm 0.12$ & 0.861 & 0.392 \\
\hline \multicolumn{5}{|l|}{ Gender (case) } \\
\hline Male & 35 & 32 & 0.126 & 0.723 \\
\hline Female & 15 & 16 & - & - \\
\hline \multicolumn{5}{|l|}{ Rutherford stage (case) } \\
\hline $1-3$ & 27 & 24 & 0.157 & 0.692 \\
\hline $4-6$ & 23 & 24 & - & - \\
\hline \multicolumn{5}{|l|}{ Diseased arteries } \\
\hline Iliac artery & 30 & 27 & 0.027 & 0.987 \\
\hline Femoral popliteal artery & 27 & 24 & - & - \\
\hline Inferior knee artery & 26 & 22 & - & - \\
\hline Smoking history (case) & 24 & 22 & 0.046 & 0.829 \\
\hline Drinking history (case) & 15 & 13 & 0.102 & 0.749 \\
\hline Hypertension (case) & 32 & 30 & 0.024 & 0.878 \\
\hline Heart disease (case) & 14 & 14 & 0.016 & 0.898 \\
\hline Diabetes mellitus (case) & 9 & 8 & 0.030 & 0.862 \\
\hline $\begin{array}{l}\text { Cerebrovascular } \\
\text { disease (case) }\end{array}$ & 12 & 11 & 0.016 & 0.899 \\
\hline $\begin{array}{l}\text { Chronic renal } \\
\text { insufficiency (case) }\end{array}$ & 16 & 12 & 0.588 & 0.443 \\
\hline Hyperlipidemia (case) & 25 & 24 & 0.163 & 0.686 \\
\hline Hypoproteinemia (case) & 30 & 29 & 0.002 & 0.966 \\
\hline Anemia (case) & 13 & 15 & 0.331 & 0.565 \\
\hline Fibrinogen $(\mathrm{g} / \mathrm{L})$ & $3.61 \pm 0.34$ & $3.58 \pm 0.32$ & 0.449 & 0.654 \\
\hline $\begin{array}{l}\text { White blood cell } \\
\text { count }\left(\times 10^{9} / \mathrm{L}\right)\end{array}$ & $7.57 \pm 1.08$ & $7.62 \pm 1.14$ & 0.223 & 0.824 \\
\hline Platelet count $\left(\times 10^{9} / \mathrm{L}\right)$ & $193.46 \pm 52.17$ & $187.59 \pm 50.68$ & 0.565 & 0.574 \\
\hline $\begin{array}{l}\text { Lymphocyte count } \\
\qquad\left(\times 10^{9} / \mathrm{L}\right)\end{array}$ & $1.72 \pm 0.68$ & $1.71 \pm 0.64$ & 0.075 & 0.940 \\
\hline
\end{tabular}

stage significantly decreased, and the vascular patency rate and total response rate significantly rose in experimental group, also with significant differences from those of control group $(p<0.05)$. After treatment, the claudication distance and ABI significantly increased in both groups compared with those before treatment $(p<0.05)$, especially in experimental group $(p<0.05)$. The incidence rates of cardiovascular and cerebrovascular events, amputation and death were significantly lower in experimental group than those in control group $(p<0.05)$ (Table 2).

\subsection{Univariate Analysis Results of Factors Affecting Prognosis}

Poor prognosis group and good prognosis group had similar gender ratio, Rutherford stage, drinking history, and numbers of cases of heart disease, cerebrovascular disease, chronic renal insufficiency, hypoproteinemia, anemia and leukocytosis $(p>0.05)$. However, the two groups had significantly different age, duration of disease, hospital stay, treatment methods, ABI, vascular patency rate, fibrinogen level, smoking history, and incidence rates of hypertension, diabetes mellitus, hyperlipidemia, thrombocytosis and lymphopenia $(p<0.05)$ (Table 3$)$.

\subsection{Multivariate Logistic Regression Analysis Results of Factors Affecting Prognosis}

According to the results of multivariate logistic regression analysis, age, conservative therapy, smoking, hypertension, diabetes mellitus, hyperlipidemia and fibrinogen were independent risk factors for the prognosis of ASO patients $(p<0.05)$ (Table 4$)$.

Table 2 Treatment outcomes $[n(\%)](\bar{x} \pm s)$

\begin{tabular}{|c|c|c|c|c|}
\hline Index & $\begin{array}{l}\text { Experimental } \\
\text { group }(n=50)\end{array}$ & $\begin{array}{c}\text { Control } \\
\text { group }(n=48)\end{array}$ & $\chi^{2} / t$ & $p$ \\
\hline $\begin{array}{l}\text { Hospitalization time } \\
\text { (days) }\end{array}$ & $12.89 \pm 1.15$ & $16.93 \pm 1.74$ & 2.157 & 0.000 \\
\hline $\begin{array}{l}\text { Claudication } \\
\text { distance }(\mathrm{m})\end{array}$ & $364.73 \pm 35.81$ & $275.68 \pm 26.54$ & 13.940 & 0.000 \\
\hline $\mathrm{ABI}$ & $0.95 \pm 0.23$ & $0.72 \pm 0.18$ & 5.498 & 0.000 \\
\hline Vascular patency rate (\%) & 95.18 & 72.60 & 15.209 & 0.000 \\
\hline Iliac artery & 29 & 20 & - & - \\
\hline $\begin{array}{l}\text { Femoral popliteal } \\
\text { artery }\end{array}$ & 26 & 18 & - & - \\
\hline Inferior knee artery & 24 & 15 & - & - \\
\hline \multicolumn{5}{|l|}{ Rutherford stage (case) } \\
\hline $1-3$ & 43 & 32 & 5.096 & 0.024 \\
\hline $4-6$ & 7 & 16 & & \\
\hline Total response rate $(\%)$ & 82.00 & 54.17 & 9.923 & 0.007 \\
\hline $\begin{array}{l}\text { Markedly effective } \\
\text { (case) }\end{array}$ & 23 & 11 & - & - \\
\hline Effective (case) & 18 & 15 & - & - \\
\hline Ineffective (case) & 9 & 22 & - & - \\
\hline $\begin{array}{l}\text { Cardiovascular and } \\
\text { cerebrovascular } \\
\text { events (case) }\end{array}$ & 3 & 10 & 4.683 & 0.030 \\
\hline Amputation (case) & 4 & 12 & 5.181 & 0.023 \\
\hline Death (case) & 2 & 8 & 4.288 & 0.038 \\
\hline
\end{tabular}


Table 3 Univariate analysis results of factors affecting prognosis $[n(\%)](\bar{x} \pm s)$

\begin{tabular}{|c|c|c|c|c|}
\hline Factors & $\begin{array}{c}\text { Poor } \\
\text { prognosis } \\
\text { group }(n=31)\end{array}$ & $\begin{array}{c}\text { Good } \\
\text { prognosis } \\
\text { group }(n=67)\end{array}$ & $\chi^{2} / t$ & $p$ \\
\hline \multicolumn{5}{|l|}{ Gender (case) } \\
\hline Male & 21 & 46 & 0.008 & 0.928 \\
\hline Female & 10 & 21 & - & - \\
\hline \multicolumn{5}{|l|}{$\begin{array}{l}\text { Rutherford stage } \\
\text { (case) }\end{array}$} \\
\hline $1-3$ & 26 & 49 & 1.360 & 0.243 \\
\hline $4-6$ & 5 & 18 & & \\
\hline Age (years) & $78.39 \pm 7.25$ & $61.42 \pm 6.27$ & 11.227 & 0.000 \\
\hline $\begin{array}{l}\text { Course of disease } \\
\text { (years) }\end{array}$ & $7.48 \pm 2.36$ & $3.54 \pm 1.21$ & 10.844 & 0.000 \\
\hline $\begin{array}{l}\text { Hospitalization time } \\
\text { (days) }\end{array}$ & $17.52 \pm 1.78$ & $11.69 \pm 1.07$ & 20.133 & 0.000 \\
\hline \multicolumn{5}{|l|}{ Treatment method } \\
\hline Interventional therapy & 8 & 42 & 11.536 & 0.001 \\
\hline $\begin{array}{l}\text { Conservative } \\
\text { treatment }\end{array}$ & 23 & 25 & - & - \\
\hline $\mathrm{ABI}$ & $0.53 \pm 0.14$ & $0.86 \pm 0.21$ & 7.958 & 0.000 \\
\hline $\begin{array}{l}\text { Vascular patency } \\
\text { rate }(\%)\end{array}$ & $32 / 52(61.54)$ & $100 / 104(96.15)$ & 31.909 & 0.000 \\
\hline Fibrinogen $(\mathrm{g} / \mathrm{L})$ & $4.76 \pm 0.51$ & $2.08 \pm 0.22$ & 36.453 & 0.000 \\
\hline Smoking (case) & 25 & 21 & 20.683 & 0.000 \\
\hline Drinking (case) & 8 & 20 & 0.170 & 0.680 \\
\hline Hypertension (case) & 28 & 34 & 14.284 & 0.000 \\
\hline Heart disease (case) & 9 & 19 & 0.005 & 0.945 \\
\hline $\begin{array}{l}\text { Diabetes mellitus } \\
\quad \text { (case) }\end{array}$ & 14 & 3 & 24.466 & 0.000 \\
\hline $\begin{array}{c}\text { Cerebrovascular } \\
\text { disease (case) }\end{array}$ & 6 & 17 & 0.427 & 0.513 \\
\hline $\begin{array}{l}\text { Chronic renal } \\
\text { insufficiency (case) }\end{array}$ & 7 & 21 & 0.797 & 0.372 \\
\hline $\begin{array}{l}\text { Hyperlipidemia } \\
\text { (case) }\end{array}$ & 29 & 20 & 34.397 & 0.000 \\
\hline $\begin{array}{l}\text { Hypoproteinemia } \\
\text { (case) }\end{array}$ & 15 & 44 & 2.643 & 0.104 \\
\hline Anemia (case) & 10 & 18 & 0.302 & 0.583 \\
\hline $\begin{array}{l}\text { Increase of white } \\
\text { blood cells (case) }\end{array}$ & 11 & 26 & 0.099 & 0.752 \\
\hline $\begin{array}{l}\text { Increase of platelets } \\
\text { (case) }\end{array}$ & 23 & 28 & 8.916 & 0.003 \\
\hline $\begin{array}{l}\text { Decrease of } \\
\text { lymphocytes (case) }\end{array}$ & 22 & 29 & 6.508 & 0.011 \\
\hline
\end{tabular}

Table 4 Multivariate logistic regression analysis results of factors affecting prognosis

\begin{tabular}{lccccc}
\hline Factors & $\boldsymbol{\beta}$ & $\mathrm{SE}$ & Wald & $\boldsymbol{p}$ & OR (95\% CI) \\
\hline Age & 0.973 & 0.825 & 3.213 & 0.011 & $1.768(1.013-2.847)$ \\
$\quad \begin{array}{l}\text { Treatment } \\
\quad \text { method }\end{array}$ & 1.468 & 0.647 & 2.548 & 0.009 & $4.126(2.527-6.638)$ \\
$\quad$ Smoking & 0.791 & 0.518 & 1.862 & 0.014 & $3.074(1.409-4.753)$ \\
$\quad \begin{array}{l}\text { Hypertension } \\
\text { Diabetes }\end{array}$ & 0.825 & 0.856 & 2.472 & 0.005 & $2.631(1.625-3.986)$ \\
$\quad$ mellitus & 2.336 & 0.732 & 4.385 & 0.008 & $4.956(3.226-6.817)$ \\
$\quad \begin{array}{l}\text { Hyperlipidemia } \\
\text { Fibrinogen }\end{array}$ & 1.573 & 0.674 & 3.191 & 0.023 & $2.278(1.343-3.751)$ \\
& 2.169 & 0.921 & 2.061 & 0.036 & $3.149(2.182-4.691)$ \\
\hline
\end{tabular}

\subsection{Continuous Variable Stratification Results}

The results of decision tree modeling revealed that the predictability was higher at the age of 70 years old and the fibrinogen level of $4 \mathrm{~g} / \mathrm{L}$, which had a greater impact on the prognosis of ASO patients $(p<0.05)$. Then age and fibrinogen level were stratified (age of $>70$ and $\leq 70$ years old, and fibrinogen level of $>4$ and $\leq 4 \mathrm{~g} / \mathrm{L}$ ). The results showed that age of $>70$ years old, fibrinogen level of $>4 \mathrm{~g} / \mathrm{L}$, conservative therapy, smoking, hypertension, diabetes mellitus and hyperlipidemia were high-risk factors for poor prognosis (Figure 1).

\section{DISCUSSION}

Interventional therapy characterized by minimal invasion, high safety, good efficacy and easy recovery, mainly including thrombolysis, balloon dilation, endoluminal atherectomy, stent placement and artery reconstruction, has been widely applied recently [5]. In this study, experimental and control groups had comparable baseline clinical data $(p>0.05)$. The hospital stay of experimental group was significantly shorter than that of control group $(p<$ $0.05)$. After treatment, the Rutherford stage significantly reduced $(p<0.05)$, and the vascular patency rate and total response rate significantly rose in experimental group, which were also significantly different from those of control group $(p<0.05)$, being consistent with the results of Zhang and Zhang [6]. Moreover, after treatment, the claudication distance and ABI significantly increased in both groups compared with those before treatment $(p<0.05)$. Meanwhile, they were significantly better in experimental group than those in control group $(p<0.05)$, being in accordance with the findings of Li et al. [7]. Interventional therapy effectively dilates and reconstructs the stenosed and even occluded blood vessels of patients, and improves the blood circulation, thereby markedly elevating the vascular patency rate. As a result, the Rutherford stage decreased, and the claudication distance, $A B I$ and total response rate increased significantly. Although conservative therapy can also

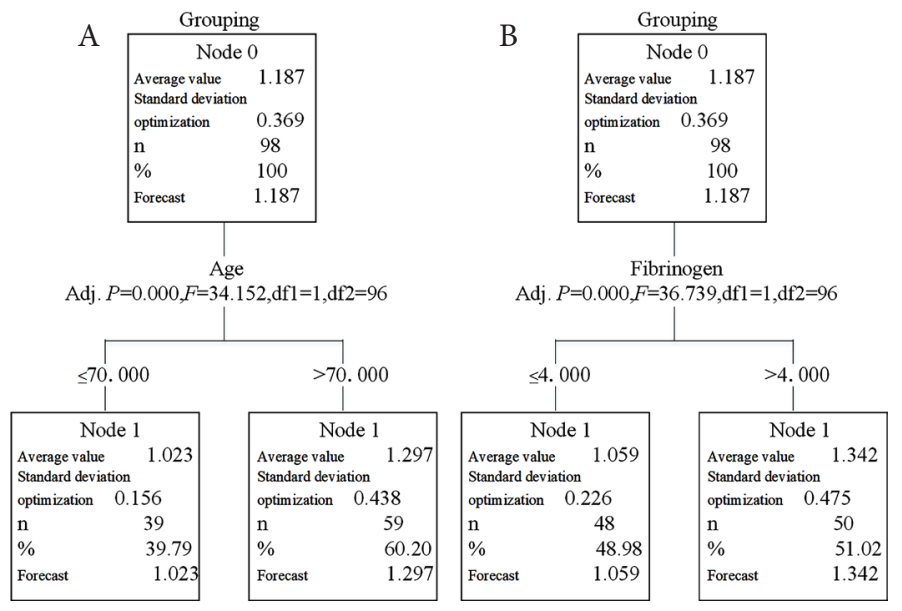

Figure 1 Decision tree model analysis of continuous variable stratification nodes. Node A represents age: age of $>70$ years old has a greater impact on prognosis. Node B indicates fibrinogen: fibrinogen level of $>4 \mathrm{~g} / \mathrm{L}$ has a greater impact on prognosis. 
improve the microcirculation, it works slowly, so the hospital stay is prolonged. In this study, the incidence rates of cardiovascular and cerebrovascular events, amputation and death were significantly lower in experimental group than those in control group $(p<0.05)$. Thus, interventional therapy was safer for ASO, being in line with a previous literature [8].

Although the limb salvage rate and survival rate of patients with ASO have been significantly raised in recent years, adverse events such as cardiovascular and cerebrovascular diseases, amputation and death still occur [9]. As a systemic disease, ASO is often accompanied by heart disease, diabetes mellitus and cerebrovascular diseases. Patients with severe lower limb ischemia suffer from ulceration and gangrene that cause amputation, and may die due to aggravated comorbidities [10]. Therefore, it is of great significance to analyze the risk factors for prognosis and to take effective measures for prevention and treatment as early as possible. In this study, the patients were divided into poor prognosis and good prognosis groups. The two groups had similar gender ratio, Rutherford stage, drinking history, and numbers of cases of heart disease, cerebrovascular disease, chronic renal insufficiency, hypoproteinemia, anemia and leukocytosis $(p>0.05)$. Nevertheless, they had significantly different age, duration of disease, hospital stay, treatment methods, $\mathrm{ABI}$, vascular patency rate, fibrinogen level, smoking history, and incidence rates of hypertension, diabetes mellitus, hyperlipidemia, thrombocytosis and lymphopenia $(p<0.05)$.

Then the above factors with significant differences were incorporated into multivariate logistic regression analysis. The analysis revealed that age, conservative therapy, smoking, hypertension, diabetes mellitus, hyperlipidemia and fibrinogen were independent risk factors for the prognosis of ASO patients $(p<0.05)$. Similarly, it has recently been reported that the incidence rate of ASO rose with increasing age, particularly in people aged $>70$ years old [11]. It has been confirmed that interventional therapy was significantly superior to conservative therapy in terms of clinical effect and prognosis [12]. Smoking increases the incidence rate of vascular restenosis, so the risks of severe lower limb ischemia and amputation rise. Smoking capacity has been positively correlated with severity of disease [13]. Atherosclerosis is the main cause for ASO. Hyperglycemia can lead to abnormal hormone secretion, vascular endothelial cell dysfunction and platelet dysfunction, thereby resulting in atherosclerosis [14]. Hypertension, especially high systolic blood pressure, has a stronger correlation with ASO, but its risk is lower than those of smoking and diabetes mellitus [15]. Moreover, hyperlipidemia can increase the risk of intermittent claudication, thus raising the prevalence rate of ASO [16]. Fibrinogen is a key coagulation factor in the blood, and the elevation of its level can cause atherosclerosis [17].

Decision tree modeling is commonly used to predict the outcome variables according to independent variables. The cut-off point of continuous variable stratification is determined by CHAID decision tree analysis, using $\alpha=0.05$ as the test level. The variables are further stratified until $p>0.05$ [18]. In this study, the analysis results showed that age of $>70$ years old and fibrinogen level of $>4 \mathrm{~g} / \mathrm{L}$ had a greater impact on the prognosis of ASO patients. In addition, conservative therapy, smoking, hypertension, diabetes mellitus and hyperlipidemia were high-risk factors for poor prognosis.

\section{CONCLUSION}

In conclusion, ASO can be safely and effectively treated by interventional therapy, with easy recovery and mild complications. The poor prognosis of ASO patients is caused by old age, conservative therapy, smoking, hypertension, diabetes mellitus, hyperlipidemia and elevated fibrinogen level. Patients should quit smoking as soon as possible after interventional therapy, and corresponding measures that reduce blood pressure, glucose and lipid levels can be taken to reduce the recurrence rate, aiming to obtain a good prognosis.

\section{CONFLICTS OF INTEREST}

The authors declare they have no conflicts of interest.

\section{AUTHORS' CONTRIBUTION}

LC and XZ designed this study and prepared this manuscript. FJ, ZY, JX, CR and LX collected and analyzed clinical data. All authors approved the final version of this manuscript.

\section{ACKNOWLEDGMENT}

This study was not financially supported.

\section{REFERENCES}

[1] Xie R, Feng YY, Wen YT, Ren W. Expression of RCAN1 and CnA in tissues of in-stent restenosis after intervention of lower extremity arteriosclerosis obliterans and its significance. J Shanghai Jiaotong Univ (Med Sci) 2017;37:298-304.

[2] Tegn N, Abdelnoor M, Aaberge L, Ranhoff AH, Endresen K, Gjertsen E, et al. Health-related quality of life in older patients with acute coronary syndrome randomised to an invasive or conservative strategy. The After Eighty randomised controlled trial. Age Ageing 2018;47:42-7.

[3] Bisdas T, Borowski M, Torsello G, First-Line Treatments in Patients With Critical Limb Ischemia (CRITISCH) Collaborators. Current practice of first-line treatment strategies in patients with critical limb ischemia. J Vasc Surg 2015;62:965.e3-73.e3.

[4] Guo J, Guo L, Dardik A, Tong Z, Xing Y, Cai Z, et al. Analysis of 17 years of surgical treatment for chronic limb ischemia in a Chinese National Clinical Center for Geriatric Disorders (2002 to 2018). Int J Cardiol 2020;318:39-42.

[5] Cai Z, Guo L, Qi L, Cui S, Tong Z, Guo J, et al. Midterm outcome of directional atherectomy combined with drug-coated balloon angioplasty versus drug-coated balloon angioplasty alone for femoropopliteal arteriosclerosis obliterans. Ann Vasc Surg 2020;64:181-7.

[6] Zhang MX, Zhang ZX. [Application value of interventional therapy in lower extremity arteriosclerosis obliterans]. China Modern Doctor 2019;57:5-7, 13.

[7] Li RS, Xing ZJ, Zhao H, Hao GQ, Zheng X, Deng ZH. [Effect and experience analysis of interventional therapy for arteriosclerosis obliterans of lower extremities]. China Pract Med 2018;13:73-4. 
[8] Yao W, Wang L, Chen Q, Wang F, Feng N. Effects of valsartan on restenosis in patients with arteriosclerosis obliterans of the lower extremities undergoing interventional therapy: a prospective, randomized, single-blind trial. Med Sci Monit 2020;26:e919977.

[9] Higashi Y, Miyata T, Shigematsu H, Origasa H, Fujita M, Matsuo $\mathrm{H}$, et al. Two-year follow-up of vascular events in peripheral arterial disease treated with antiplatelet agents: a prospective observational multicenter cohort study (SEASON). Sci Rep 2017;7:6095.

[10] Song XT, Liu B, Liu CW, Ni L, Zeng R, Ye W, et al. [Prevalence of asymptomatic carotid artery stenosis in patients with arteriosclerosis obliterans of lower extremities and risk factor analysis]. Zhonghua Yi Xue Za Zhi 2016;96:126-8.

[11] Chen WN, Guo SN, Wang JY, Jia LQ, Li DY, Tian Y. [Correlation between autophagy and polarization of macrophages in atherosclerosis plaque in arteriosclerosis obliterans amputees]. Yao Xue Xue Bao 2016;51:68-74 [Article in Chinese].

[12] Zhou Y, Zhang NR, Zheng ZN, Yang Y, Lyu BF, Wang HL, et al. Regular transient limb ischemia prevents atherosclerosis progression in hypercholesterolemic rabbits. Chin Med J (Engl) 2019;132:1079-86.
[13] Chiang IH, Chen SG, Tzeng YS. Treatment of thromboangiitis obliterans using smoking cessation and far-infrared therapy: a case study. Ostomy Wound Manage 2017;63:20-3.

[14] Hemsinli D, Altun G, Kaplan ST, Yildirim F, Cebi G. Hyperbaric oxygen treatment in thromboangiitis obliterans: a retrospective clinical audit. Diving Hyperb Med 2018;48:31-5.

[15] Taneja Y, Ram P, Dhaked SK, Sen TK. Squamous cell carcinoma penis in a case of urethral stricture due to lichen sclerosus balanitis xerotica obliterans: a case report and review of literature. J Clin Diagn Res 2017;11:PD17-PD18.

[16] Argyropoulou OD, Protogerou AD, Sfikakis PP. Accelerated atheromatosis and arteriosclerosis in primary systemic vasculitides: current evidence and future perspectives. Curr Opin Rheumatol 2018;30:36-43.

[17] Ertugrul AS, Bozoglan A, Taspinar M. The effect of nonsurgical periodontal treatment on serum and gingival crevicular fluid markers in patients with atherosclerosis. Niger J Clin Pract 2017;20:361-8.

[18] Önder E, Uyar Ş. CHAID analysis to determine socioeconomic variables that explain students' academic success. Univers J Educ Res 2017;5:608-19. 